\title{
Ambição domesticada
}

\author{
Giovanna Lícia Rocha Triñanes Aveiro
}

RONSINI, V. V. M.

A crença no mérito e a desigualdade:

a recepção da telenovela

do horário nobre.

Porto Alegre: Sulina, 335 p., 2012.

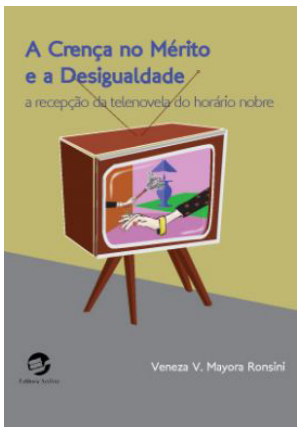

Resumo: O livro de Veneza Ronsini apresenta os resultados de uma pesquisa comparativa de recepção de telenovelas do horário nobre, com jovens das classes popular, média e alta. A questão investigada trata das relações entre o consumo da mídia e as apropriações diferenciadas dos sentidos da desigualdade social, da pobreza e da ideologia meritocrática para a reprodução e a legitimação da hierarquia social. A pesquisa se fundamenta no modelo das mediações de Jesús Martín-Barbero e no modelo teórico de Stuart Hall de codificação/decodificação, aplicados à análise tanto das narrativas das telenovelas quanto da recepção. Por fim, o livro argumenta pela retomada do conceito de classe social no campo dos estudos culturais.

Palavras-chave: estudos culturais; recepção; telenovela; jovens; classe social.

Abstract: Domesticated ambition - Veneza Ronsini's book presents the results of a comparative survey of primetime soap operas reception, among youngsters of popular, middle and upper classes. The matter investigated is the relationship between media consumption and the differentiated appropriations of social inequality sense, poverty and meritocratic ideology for reproduction and legitimation of social hierarchy ideology. The research is based on the mediation's model of Jesús Martín-Barbero and Stuart Hall's theoretical model of encoding/decoding applied to the analysis of both the soap operas narratives and their reception. Finally, the book argues for the resumption of the concept of social class in the Cultural Studies.

Keywords: cultural studies; reception; soap opera; youth; social class. 
A crença no mérito e a desigualdade: a recepção da telenovela do horário nobre, de Veneza Ronsini, publicado em 2012 pela editora Sulina de Porto Alegre, tem origem na pesquisa empírica realizada pelo grupo Mídia, recepção e consumo cultural (UFSM), de 2007 a 2010, sob a liderança da autora e com apoio do CNPq. Trata-se de um estudo de abordagem sociocultural sobre a recepção da telenovela entre jovens das classes popular, média e alta, a fim de apreender apropriações diferenciadas da mídia a respeito da organização social brasileira. Ao final da pesquisa, o vínculo com a classe social se mostra inescapável.

O livro é dividido em duas partes, cada uma com três capítulos. A primeira parte conduz o leitor desde o referencial teórico adotado até a leitura das representações da pobreza e da desigualdade em novelas das oito da Rede Globo. A segunda parte apresenta os resultados e o exame da pesquisa empírica de recepção realizada com 48 jovens de Santa Maria (Rio Grande do Sul), estabelecendo um comparativo entre suas percepções de mundo.

Filiada aos estudos culturais, Ronsini conjuga o modelo das mediações de Jesús Martín-Barbero e o modelo teórico de Stuart Hall de codificação/decodificação numa proposta teórico-metodológica aplicada à análise da recepção. A autora defende a retomada da noção de classe social nesse campo, sobretudo como mediação, que é atravessada por outras posições sociais dos sujeitos (gênero, etnia, idade, etc.).

Nas décadas de 1990 e 2000, apenas três trabalhos acadêmicos sobre recepção de abordagem sociocultural consideraram a mediação da classe social, sem, no entanto, trabalha-la nas conclusões da pesquisa. Para a autora, "a diferença de classe articula todas as demais e se manifesta no habitus" (RONSINI, 2012, p. 40). A teoria da reprodução de Bourdieu fundamenta a posição assumida na pesquisa de que os agentes nunca são sujeitos absolutos de suas práticas. Assim, o habitus de classe mostra as diferenças objetivas que são materializadas nas "disposições inscritas nos modos de ser", fazer e pensar dos sujeitos (ibid., p. 83).

O diálogo com Jessé de Souza é central para a compreensão da especificidade da modernidade periférica brasileira. Segundo Souza, a reprodução da desigualdade é explicada e legitimada pela ideologia meritocrática, que classifica pessoas de acordo com "qualificação individual, posição social e renda: indicadores do desempenho individual que legitimam a posição de classe ocupada em termos do mérito individual e também legitimam o permanente acesso diferencial às chances de vida e de apropriação de bens" (SOUZA apud RONSINI, 2012, p. 41-42). As experiências de classe impedem, portanto, o acesso homogêneo à mundialização da cultura.

Os aparatos tecnológicos de comunicação têm seu lugar nessa representação e na justificação do mundo social, pois geram formas simbólicas que reproduzem modos de vida e definem relações entre grupos e classes sociais. As telenovelas se destacam como objeto para essa pesquisa comparativa, na medida em que compõem um acervo compartilhado pelas classes popular, média e alta. Assim, é possível ver "a apropriação diferenciada da cultura midiática comum" (ibid., p. 96). 
Outro aspecto importante das telenovelas analisadas é a inserção das classes populares em seus repertórios. Para Ronsini, essa inclusão se deve à melhoria de renda das classes D e E. Ao opor núcleo rico e núcleo pobre, os temas da pobreza, desigualdade e da meritocracia ganham ênfase nas narrativas. Na análise das codificações das novelas Páginas da Vida, Paraíso Tropical, Duas Caras, A Favorita e Caminho das Índias, a autora afirma que

é com base nos valores dominantes que se estabelecem os valores e as posições das demais classes. Assim, por exemplo, o estilo da vida popular é representado "naturalmente" como espontâneo (sem formalismos); comunitário em contraposição ao competitivo mundo das classes altas; utilitário [...] em contraposição ao estético; rude em contraposição ao elaborado; "barroco" em contraposição ao sóbrio; desinteressado em contraposição ao interessado; emocional em contraposição ao civilizado; corporal em contraposição ao intelectual; sexual em contraposição ao mental. (lbid., p. 108)

Os conflitos entre as classes são subsumidos em relações de afeto, seja na formação de um casal composto por rico e pobre ou pela amizade entre empregados e patrões, que ocultam a desigualdade via ideologia do desempenho e do fatalismo. A autora aponta, portanto, que a principal contribuição da mídia nesse quadro é a crença no mito da ascensão social mediante competências pessoais, em detrimento de qualquer circunstância.

A pesquisa de recepção abarcou entrevistas, aplicação de formulário e observação em escolas e residências, totalizando 48 jovens abordados, sendo vinte da classe popular (de 15 a 18 anos, com faixa de renda entre $R \$ 511,00$ e $R \$ 1.278,00$ ), vinte da classe média e média baixa (de 14 a 18 anos, com faixa de renda entre $R \$ 2.500,00$ e $R \$ 6.500,00$ ) e oito da alta (de 14 a 17 anos, com faixa de renda entre $\mathrm{R} \$ 8.000,00$ e $\mathrm{R} \$ 10.000,00$ ). Veneza constrói um retrato detalhado sobre os habitus de cada classe: experiências de consumo da mídia e da cultura, escolaridade dos pais, perfil socioeconômico das famílias e usufruto de bens de consumo, correlacionados à mediação da família e da escola. Dentre os resultados apresentados na segunda parte do livro, alguns merecem destaque.

Entre os jovens das classes popular e média, as telenovelas têm papel de educadoras sobre os estilos de vida das outras classes, mais altas, naturalizando seus valores e comportamentos. Cabe apontar que os jovens da classe popular não se identificam como pobres e sim como classe média. Veneza explica esse fato pela proximidade das experiências de consumo dos jovens dessas duas classes, cujos bens desejados, assim como o anseio por carreiras de sucesso e ascensão social, são também apreendidos na assistência das telenovelas.

A escola, no entanto, somente na classe popular se mostrou mediadora importante para a formação de uma consciência crítica com relação à representação da desigualdade social. São esses jovens que têm maior número de posicionamentos críticos sobre a questão considerada estrutural, não individual, e também apontam diferenças entre a vida real e as figuras de ricos e pobres retratados na telenovela. 
Outro aspecto importante sobre a consciência crítica da classe popular é que os sonhos aventados pela mídia não obliteram seu descompasso com as dificuldades que esses sujeitos e suas famílias enfrentam na vida cotidiana. Para os jovens da classe média entrevistados, essa ruptura se materializa ao fracassarem nas provas do vestibular para o curso e/ou universidade que lhes garantiria mudança de status social.

É possível pensar aqui no argumento de Žižek (2010, p. 50) a respeito da "irracionalidade" do sucesso ou do fracasso no capitalismo de mercado: "a própria injustiça do capitalismo é um traço essencial que o torna tolerável para a maioria (posso aceitar meu fracasso muito mais facilmente se sei que ele não se deve às minhas qualidades inferiores)".

O estudo dessas injustiças, através do consumo das telenovelas, foi o caminho trilhado por Veneza Ronsini para explicar "uma existência dividida entre os sonhos de autorrealização e os limites das necessidades mais prementes" (ibid., p. 11), conforme breve relato autobiográfico partilhado no início de seu livro. Assim, de forma primorosa, a autora torna incontestável trabalhar com tais desvantagens, fornecendo uma grande contribuição aos estudos de recepção e às lacunas observadas nos estudos culturais.

Em última instância, Veneza nos convida ao exame crítico das mazelas contemporâneas que nos constroem: "em tempos nos quais vigora o imperativo da felicidade (FREIRE FILHO, 2010), poucos querem admitir as dificuldades que atravessam, a não ser para dizer que são fortes e que as superam" (ibid., p. 12).

Giovanna Lícia R. T. Aveiro é mestranda do Programa de Estudos Pós-Graduados em Comunicação e Semiótica da PUC-SP e bolsista do CNPq; graduada em ciências sociais pela UFSC.

giovanna_licia@hotmail.com

\section{Referências}

FREIRE FILHO, João (Org). A felicidade na era de sua reprodutibilidade científica: construindo "pessoas cronicamente felizes". In: . (Org). Ser feliz hoje. Reflexões sobre o imperativo da felicidade. Rio de Janeiro: FGV; Globo Universidade, 2010.

ŽIŽEK, S. Como ler Lacan. Rio de Janeiro: Zahar, 2010. 